\title{
Two distinct strategies of cotton and soybean differing in leaf movement to perform photosynthesis under drought in the field
}

\author{
Ya-LiZhang ${ }^{\mathrm{A}}$, Yuan-Yuan Hu${ }^{\mathrm{A}}$, Hong-HaiLuo $^{\mathrm{A}}$, Wah Soon Chow ${ }^{\mathrm{B}}$ and Wang-Feng Zhang ${ }^{\mathrm{A}, \mathrm{C}}$ \\ AThe Key Laboratory of Oasis Eco-agriculture, Xinjiang Production and Construction Group, Shihezi University, \\ Shihezi, 832003, PR China. \\ ${ }^{B}$ Division of Plant Science, Research School of Biology, College of Medicine, Biology and Environment, \\ The Australian National University, Canberra, ACT 0200, Australia. \\ ${ }^{\mathrm{C}}$ Corresponding author. Email: zwf_shzu@163.com
}

\begin{abstract}
This paper reports an experimental test of the hypothesis that cotton and soybean differing in leaf movement have distinct strategies to perform photosynthesis under drought. Cotton and soybean were exposed to two water regimes; drought stressed and well watered. Drought-stressed cotton and soybean had lower maximum $\mathrm{CO}_{2}$ assimilation rates than well-watered (control) plants. Drought reduced the light saturation point and photorespiration of both species - especially in soybean. Area-based leaf nitrogen decreased in drought-stressed soybean but increased in drought-stressed cotton. Drought decreased PSII quantum yield $\left(\Phi_{\text {PSII }}\right)$ in soybean leaves, but increased $\Phi_{\text {PSII }}$ in cotton leaves. Drought induced an increase in light absorbed by the PSII antennae that is dissipated thermally via $\Delta \mathrm{pH}$ - and xanthophylls-regulated processes soybean leaves, but a decrease in cotton leaves. Soybean leaves appeared to have greater cyclic electron flow (CEF) around PSI than cotton leaves and drought further increased CEF in soybean leaves. In contrast, CEF slightly decreased in cotton under drought. These results suggest that the difference in leaf movement between cotton and soybean leaves gives rise to different strategies to perform photosynthesis and to contrasting photoprotective mechanisms for utilisation or dissipation of excess light energy. We suggest that soybean preferentially uses light-regulated non-photochemical energy dissipation, which may have been enhanced by the higher CEF in drought-stressed leaves. In contrast, cotton appears to rely on enhanced electron transport flux for light energy utilisation under drought, for example, in enhanced nitrogen assimilation.
\end{abstract}

Additional keywords: diaheliotropic, paraheliotropic, photoprotection, water deficit.

\section{Introduction}

Cotton (Gossypium hirsutum L.) and soybean (Glycine max L.) track sunlight continually throughout the day. Cotton exhibits diaheliotropic leaf movement (turning perpendicular to the light), maintaining leaf diaheliotropic movement up to the wilting point of the plant. Soybean exhibits both diaheliotropic and paraheliotropic leaf movements, exhibiting increasing paraheliotropic movement (intercepting less light) as leaf water potential declines (Ehleringer and Forseth 1980; Ehleringer and Hammond 1987; Kao and Tsai 1998; Pastenes et al. 2004; Pastenes et al. 2005). This results in quite different incident solar radiation levels and microclimatic conditions for soybean and cotton, especially during drought (Isoda and Wang 2002). Similar phenomena were also reported on the desert winter annuals, Arizona lupine (Lupinus arizonicus S.Watson) and Desert Fivespot (Malvastrum rotundifolium A.Gray) (Forseth and Ehleringer 1982b).

The capacity to utilise the light energy absorbed by the photosynthetic apparatus typically decreases in plants subjected to drought, resulting in absorption of light energy in greater excess of that needed for carbon assimilation. Excessive light energy absorption is likely to induce photoinhibition of photosynthesis and to cause damage from an over-energisation of the photosynthetic apparatus (e.g. Oguchi et al. 2011). However, plants have evolved various photoprotection mechanisms to protect against photodamage (Long et al. 1994). Cotton leaves have a strong capacity, for example, via photorespiration and thermal emission, to dissipate excessive light energy that can otherwise damage the photosynthetic apparatus (Perry et al. 1983; Björkman and Demmig-Adams 1994; Kornyeyev et al. 2005). Furthermore, a higher electron transport capacity occurs in cotton leaves developed under long-term drought (Kitao and Lei 2007; Massacci et al. 2007). In contrast, soybean adapts to drought by dissipating the excess excitation energy thermally with the downregulation of PSII activity to protect its photosynthetic apparatus from the photodamage. This photoprotective mechanism may be assisted by paraheliotropic leaf movement, which reduces incident light on the leaf (Kao and Forseth 1992; Bielenberg et al. 2003; Inamullah and Isoda 2005a, 2005b; Arena et al. 2008). Therefore, as a consequence of this difference leaf orientational movement, the two crops should exhibit different acclimation strategies in response to drought in terms of 
tranpiration and photoprotection (Inamullah and Isoda 2005a, 2005b). Sailaja and Ramadas (1996) proposed that the mechanisms of protection are different in diaheliotropic and parahelitropic plants for improving photosynthetic performance. Previous work on L. arizonicus and M. rotundifolium (the former has diaheliotropic leaf movement, whereas the latter has diaheliotropic and parahelitropic leaf movement) has shown that the two species exhibits different photosynthetic acclimation response to growth temperature and drought (Forseth and Ehleringer 1982a, 1983). Therefore, it seems likely that photosynthetic activity of cotton and soybean differing in leaf movement would also respond differently to drought due to differences in light interception by the leaves.

Our study was undertaken to test this hypothesis by comparing the photosynthetic characteristics of soybean and cotton. Three main facets were investigated in this study, namely, the differences between cotton and soybean under drought in terms of (1) the ability of the photosynthetic apparatus to utilise light energy, (2) the partitioning of absorbed light energy and (3) the distribution of photosynthetic electron flow between linear and cyclic transport.

\section{Materials and methods}

The experiment was conducted in an experimental field of Shihezi Agricultural College, Shihezi University, Xinjiang, China $\left(45^{\circ} 19^{\prime} \mathrm{N}, 8^{\circ} 03^{\prime} \mathrm{E}\right)$ in 2008. Cotton (Gossypium hirsutum L. cv. Xinluzao 13) and soybean (Glycine max L. cv. Xindadou 1) seeds were sown on 24 April and plants were grown under field conditions with under-mulch drip irrigation. Figure 1 shows the meteorological conditions in terms of maximum and minimum temperature and precipitation during the crop growing season. The experimental design was a split-plot in randomised complete blocks (three replications) with the two

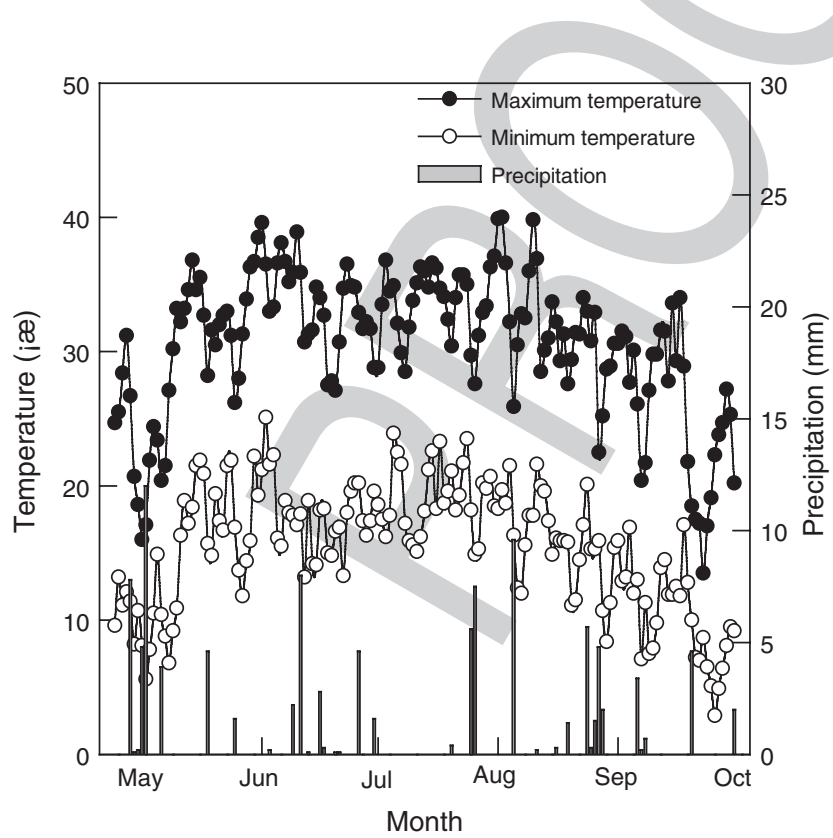

Fig. 1. Maximum and minimum temperature and percipitation at the study area. water regimes as the main plot and two crops as the subplot and the subplot area was $60 \mathrm{~m}^{2}$. There were two levels of irrigating water, namely, well-watered treatment and drought-stressed treatment. The well-watered plots were irrigated according to standard local practice whereas the drought-stressed plots were irrigated to the extent of $20 \%$ of the well-watered plots after sowing. Weeds and pests were controlled in the field using standard management practices.

Measurements were conducted at the seed development stage in soybean and at the boll formation stage in cotton. For the measurements, plants were selected at random and from each selected plant, the terminal leaflet of the main stem in soybean and the topmost fully expanded leaf on the main stem in cotton were chosen.

\section{Leaf water potential}

Leaf water potential was measured with a pressure chamber (SKPM 1400; Skye Instruments, Llandrindod Wells, UK) at predawn. The leaf lamina was enclosed in the chamber and subjected to increasing pressure from a compressed nitrogen cylinder until free sap was visible at the petiole outside the chamber.

\section{Dual measurements of PSII and PSI photochemical efficiency}

Simultaneous measurements of PSII and PSI photochemical efficiency were made using a saturation-pulse Dual-PAM-100 fluorometer (Walz, Effeltrich, Germany). Prior to measurement, leaves were dark-adapted sufficiently (for $\sim 1 \mathrm{~h}$ ). $F_{\mathrm{o}}, F_{\mathrm{m}}$ and $P_{\mathrm{m}}$ were recorded. Each leaf was illuminated with an actinic light of $1033 \mu \mathrm{mol} \mathrm{m}{ }^{-2} \mathrm{~s}^{-1}$ for $4-5 \mathrm{~min} . F_{\mathrm{s}}, F_{\mathrm{m}}{ }^{\prime}$ and $P_{\mathrm{m}}{ }^{\prime}$ were then measured, the latter two with a saturating light pulse. The intensity and the width of saturating pulse were $10000 \mu \mathrm{mol} \mathrm{m}^{-2} \mathrm{~s}^{-1}$ and $600 \mathrm{~ms}$, respectively. Then, rapid light curves were obtained with the Dual-PAM 100 using an internal program and PAR supplied by red light-emitting diodes. Nine discrete PAR steps were used (20 s each): 11, 42, 131, 344, 536, 830, 1292, 1599 and $1957 \mu \mathrm{mol} \mathrm{m}^{-2} \mathrm{~s}^{-1}$. Each light increment was followed by the measurement of $F_{\mathrm{s}}$, and by a saturating pulse for the measurement of $F_{\mathrm{m}}{ }^{\prime}$ and $P_{\mathrm{m}}{ }^{\prime}$.

PSII quantum yield $\left(\Phi_{\text {PSII }}\right)$ in the light was calculated as $\left(F_{\mathrm{m}}{ }^{\prime}-F_{\mathrm{s}}\right) / F_{\mathrm{m}}{ }^{\prime}$ (Genty et al. 1989). PSI quantum yield, Y(I), of photochemical energy conversion was calculated as $1-\mathrm{Y}$ (ND) - Y(NA). Y(ND) and Y(NA) were directly determined by the saturation pulse method. $\mathrm{Y}(\mathrm{ND})=1-$ P700red. and $\mathrm{Y}(\mathrm{NA})=\left(P_{\mathrm{m}}-P_{\mathrm{m}}{ }^{\prime}\right) / P_{\mathrm{m}}$ (Schreiber and Klughammer 2008). ETR (II) and ETR (I) was calculated according to the formula $\mathrm{ETR} \quad(\mathrm{II})=\Phi_{\mathrm{PSII}} \times \mathrm{PAR} \times 0.5 \times 0.84$ and $\mathrm{ETR} \quad(\mathrm{I})=\mathrm{Y}$ (I) $\times$ PAR $\times 0.5 \times 0.84$, where PAR is the photosynthetically active radiation, 0.5 is a correction factor based on the assumption that the incident photons are absorbed equally by the two photosystems, and 0.84 is the proportion of incident photons absorbed by the leaf(Schreiber et al. 1994; Schreiber and Klughammer 2008). Photochemical quenching coefficient ( $q P)$ was calculated as $\left(F_{\mathrm{m}}{ }^{\prime}-F_{\mathrm{s}}\right) /\left(F_{\mathrm{m}}{ }^{\prime}-F_{\mathrm{o}}{ }^{\prime}\right)$ (Krause and Weis 1991). Photochemical quantum yield of open PSII centers in the lightadapted state $\left(F_{\mathrm{v}}{ }^{\prime} / F_{\mathrm{m}}{ }^{\prime}\right)$ was calculated as $\left(F_{\mathrm{m}}{ }^{\prime}-F_{\mathrm{o}}{ }^{\prime}\right) / F_{\mathrm{m}}{ }^{\prime}$ (Schreiber et al. 1994). Minimal fluorescence under light 
exposure $\left(F_{\mathrm{o}}{ }^{\prime}\right)$ was calculated according to Oxborough and Baker (1997) using the equation $F_{\mathrm{o}}{ }^{\prime}=F_{\mathrm{o}} /\left(F_{\mathrm{v}} / F_{\mathrm{m}}+F_{\mathrm{o}} / F_{\mathrm{m}}{ }^{\prime}\right)$.

The fractions of light absorbed by the PSII antennae that is lost by constitutive thermal dissipation and via fluorescence $\left(\Phi_{\mathrm{f}, \mathrm{D}}\right)$ and the fraction of light absorbed by the PSII antennae that is dissipated thermally via $\Delta \mathrm{pH}$ - and xanthophylls-regulated processes $\left(\Phi_{\mathrm{NPQ}}\right)$ were calculated as $F_{\mathrm{s}} / F_{\mathrm{m}}$ and $\left(F_{\mathrm{s}} / F_{\mathrm{m}}{ }^{\prime}\right)-$ $\left(F_{\mathrm{s}} / F_{\mathrm{m}}\right)$, respectively (Hendrickson et al. 2004).

\section{Gas exchanges and leaf nitrogen content}

Leaf $\mathrm{CO}_{2}$ assimilation rates were determined with a Li-6400 IRGA (Model LI-6400, Li-Cor Inc., Lincoln, NE, USA). Leaf $\mathrm{CO}_{2}$ assimilation rate was measured after equilibration (obtain the steady-state of photosynthesis rate) at each PAR in a sequence of $2000,1800,1500,1200,800,500,300,200,100,50,30$ and $0 \mu \mathrm{mol}$ photons $\mathrm{m}^{-2} \mathrm{~s}^{-1}$ at leaf temperature $\sim 33^{\circ} \mathrm{C}$. Illumination was provided by a red/blue LED source (LI 6400-02B, Li-Cor Inc.).

$\mathrm{CO}_{2}$ assimilation rate was measured at two $\mathrm{O}_{2}$ concentrations $\left(21 \% \mathrm{O}_{2}+\sim 360 \mu \mathrm{mol} \mathrm{CO} \mathrm{mol}^{-1}\right.$, and $2 \% \mathrm{O}_{2}+\sim 360 \mu \mathrm{mol} \mathrm{CO}$ $\mathrm{mol}^{-1}$ ) under $1600 \mu \mathrm{mol}$ photons $\mathrm{m}^{-2} \mathrm{~s}^{-1}$ to calculate photorespiration. Photorespiration rate was estimated as $\mathrm{CO}_{2}$ assimilation rate at low $\mathrm{O}_{2}$ concentrations minus $\mathrm{CO}_{2}$ assimilation rate at normal $\mathrm{O}_{2}$ concentrations.

The Kjeldahl method was used to determine leaf nitrogen content (Schuman et al. 1972).

\section{Data analyses}

Significant effects due to water treatment, crop and the interaction terms were tested using two-way ANOVA using SPSS 16.0 for Windows (Chicago, IL, USA).

\section{Results}

Light response curves, photorespiration and derived parameters

Figure 2 shows typical photosynthesis-PAR response curves of both soybean and cotton. Cotton had higher $\mathrm{CO}_{2}$ assimilation

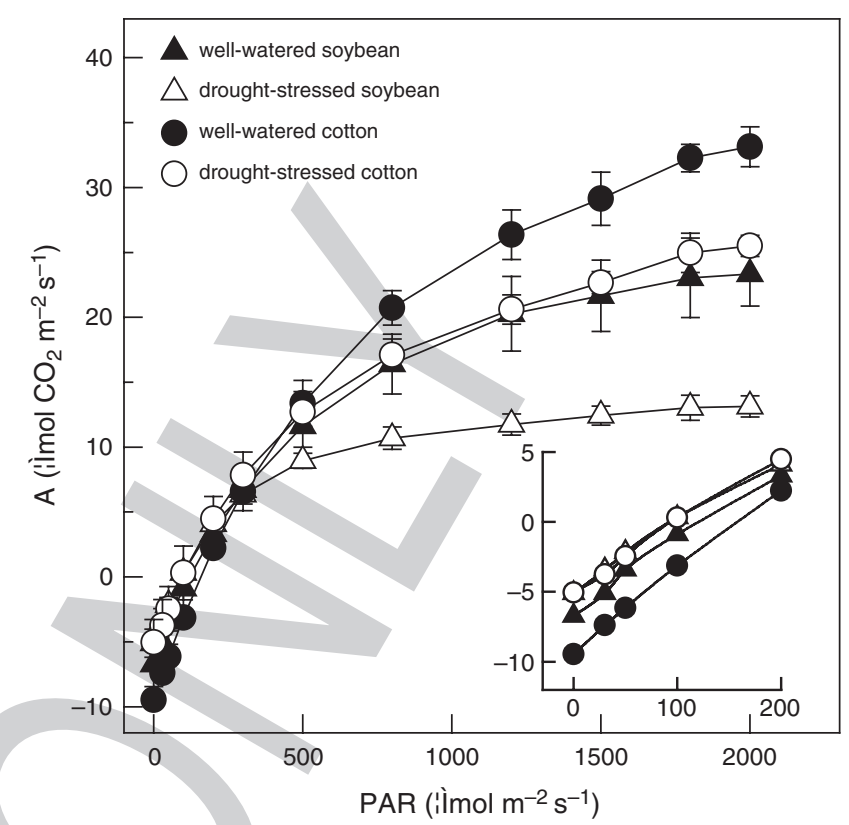

Fig. 2. Light response curves of well-watered soybean, drought-stressed soybean, well-watered cotton and drought-stressed cotton. Values are means \pm s.e. $(n=3)$.

rate than soybean. $\mathrm{CO}_{2}$ assimilation rates in both species decreased significantly in drought-stressed treatments, soybean showing a larger decrease than cotton. Light saturation point (LSP), light compensation point (LCP), maximum $\mathrm{CO}_{2}$ assimilation rate $\left(A_{\max }\right)$, apparent quantum efficiency ( $\left.\mathrm{AQE}\right)$ and dark respiration $\left(R_{\mathrm{d}}\right)$ derived from light response curves are presented in Table 1. LSP was significantly higher $(P<0.01)$ in cotton plants than in soybean plants under control conditions, and was reduced by 43 and $13 \%$ in drought-stressed soybean and cotton plants, respectively. Both LCP and $R_{\mathrm{d}}$ were decreased by drought-stress treatment in both species, but especially in cotton. Neither LCP nor $R_{\mathrm{d}}$ were significantly

Table 1. Predawn water potential, light saturation point (LSP), light compensation point (LCP) and maximum $\mathrm{CO}_{2}$ assimilation rate ( $\left.A_{\text {max }}\right)$ derived from light response curves, area-based leaf nitrogen $\left(N_{\text {area }}\right)$, dark respiration $\left(R_{\mathrm{d}}\right)$, photorespiration (PR), water use efficiency (WUE) and photosynthetic nitrogen utilisation efficiency (PNUE) in leaves of well-watered or drought-stressed soybean, well-watered cotton or droughtstressed cotton

WUE and PNUE were calculated as the ratio of $\mathrm{CO}_{2}$ assimilation rate to transpiration rate and the ratio of $A_{\max }$ to $N_{\text {area }}$, respectively. Significance level of main effects analysed by ANOVA for species $(\mathrm{Cv})$, water stress treatment $(\mathrm{W})$, and their interaction term are indicated: NS, $P>0.05 ; *, P \leq 0.05 ; * *, P<0.01$

\begin{tabular}{|c|c|c|c|c|c|c|c|}
\hline & \multicolumn{2}{|c|}{ Soybean } & \multicolumn{2}{|c|}{ Cotton } & \multicolumn{3}{|c|}{ ANOVA } \\
\hline & Well-watered & Drought-stressed & Well-watered & Drought-stressed & $\mathrm{Cv}$ & $\mathrm{W}$ & $\mathrm{Cv} \times \mathrm{W}$ \\
\hline Water potential (MPa) & $-1.0 \pm 0.1$ & $-1.9 \pm 0.1$ & $-1.0 \pm 0.1$ & $-2.2 \pm 0.1$ & NS & $* *$ & NS \\
\hline$N_{\text {area }}\left(\mathrm{g} \mathrm{m}^{-2}\right)$ & $2.38 \pm 0.06$ & $1.98 \pm 0.06$ & $2.58 \pm 0.13$ & $3.35 \pm 0.17$ & $* *$ & $* *$ & $* *$ \\
\hline$A_{\max }\left(\mu \mathrm{molm} \mathrm{m}^{-2} \mathrm{~s}^{-1}\right)$ & $29.9 \pm 3.0$ & $17.6 \pm 1.8$ & $43.1 \pm 1.3$ & $29.8 \pm 0.9$ & $* *$ & $* *$ & $* *$ \\
\hline $\operatorname{LSP}\left(\mu \mathrm{mol} \mathrm{m}{ }^{-2} \mathrm{~s}^{-1}\right)$ & $1736 \pm 50$ & $984 \pm 38$ & $2304 \pm 88$ & $1996 \pm 118$ & $* *$ & $*$ & $* *$ \\
\hline $\mathrm{LCP}\left(\mu \mathrm{mol} \mathrm{m}{ }^{-2} \mathrm{~s}^{-1}\right)$ & $127 \pm 28$ & $92 \pm 13$ & $161 \pm 13$ & $98 \pm 38$ & NS & $*$ & NS \\
\hline $\mathrm{AQE}\left(\mu \mathrm{mol} \mathrm{mol}{ }^{-1}\right)$ & $0.053 \pm 0.007$ & $0.055 \pm 0.006$ & $0.059 \pm 0.005$ & $0.046 \pm 0.001$ & NS & NS & $*$ \\
\hline$R_{\mathrm{d}}\left(\mu \mathrm{molm} \mathrm{m}^{-2} \mathrm{~s}^{-1}\right)$ & $-6.72 \pm 1.72$ & $-5.10 \pm 1.08$ & $-8.79 \pm 0.28$ & $-4.50 \pm 1.78$ & NS & $*$ & NS \\
\hline $\mathrm{PR}\left(\mu \mathrm{mol} \mathrm{m}{ }^{-2} \mathrm{~s}^{-1}\right)$ & $10.3 \pm 0.5$ & $2.4 \pm 0.1$ & $12.7 \pm 0.7$ & $7.2 \pm 0.6$ & $* *$ & $* *$ & $* *$ \\
\hline WUE $\left(\mu \mathrm{mol} \mathrm{mmol}{ }^{-1}\right)$ & $1.99 \pm 0.29$ & $3.95 \pm 0.8$ & $2.49 \pm 0.01$ & $2.68 \pm 0.33$ & NS & NS & $*$ \\
\hline PNUE $\left(\mu \mathrm{mol} \mathrm{g}^{-1} \mathrm{~s}^{-1}\right)$ & $12.6 \pm 1.27$ & $8.88 \pm 0.93$ & $16.69 \pm 0.49$ & $8.89 \pm 0.26$ & $* *$ & $* *$ & $* *$ \\
\hline
\end{tabular}


different, either between species or species $\times$ treatment interactions. Drought had a significant effect on $A_{\max }$ in both plants, reducing $A_{\max }$ by 41 and $31 \%$ compared with well-watered soybean and cotton plants, respectively. $A_{\max }$ was significantly different between the two plant species $(P<0.01)$ and between treatments $(P<0.01)$, showing a significant species $\times$ treatment interaction $(P<0.01)$. AQE was not significantly different either between species or treatments, but species $\times$ treatment interaction was significantly different $(P<0.05)$. A significantly $(P<0.01)$ lower photorespiration rate was found in droughtstressed plants than in well-watered plants; cotton plants had higher photorespiration than soybean in both treatments. Drought significantly increased water use efficiency (WUE) in soybean leaves. WUE was no different between the two plant species or between treatments, but showed a significant species $\times$ treatment interaction $(P<0.05)$.

\section{Leaf water potential, area-based nitrogen and photosynthetic nitrogen utilisation efficiency}

As shown in Table 1, predawn leaf water potential revealed a significant decrease $(P<0.01)$ from well-watered to droughtstressed conditions in both soybean and cotton plants. Cotton had higher area-based leaf nitrogen $\left(N_{\text {area }}\right)$ and photosynthetic nitrogen utilisation efficiency (PNUE) than soybean. $N_{\text {area }}$ of soybean decreased in drought-stressed plants whereas that of cotton increased in drought-stressed plants. PNUE in both plants decreased significantly in drought-stressed treatments, cotton showing a larger decrease than soybean. $N_{\text {area }}$ and PNUE were significantly different between cotton and soybean plants $(P<0.01)$ and between water treatments $(P<0.01)$, and showed a significant species $\times$ treatment interaction $(P<0.01)$.

\section{Photochemistry}

The partitioning of absorbed light energy in cotton and soybean leaves was evaluated in response to drought (Fig. 3). In soybean and cotton leaves, $\Phi_{\text {PSII }}$ decreased with increase in PAR, $\Phi_{\text {PSII }}$ being higher in cotton than in soybean. Drought decreased $\Phi_{\mathrm{PSII}}$ in soybean leaves (Fig. $3 a, b$ ), but increased $\Phi_{\text {PSII }}$ in cotton leaves (Fig. $3 c, d$ ). $\Phi_{\mathrm{NPQ}}$ increased with PAR, and was higher in soybean than in cotton. Drought induced an increase in $\Phi_{\mathrm{NPQ}}$ in soybean leaves (Fig. $3 a, b$ ), but a reduction in $\Phi_{\mathrm{NPQ}}$ in cotton leaves (Fig. $3 c, d$ ). $\Phi_{\mathrm{f}, \mathrm{D}}$ increased marginally at intermediate light in both plants, and drought induced lower $\Phi_{\mathrm{f}, \mathrm{D}}$ in soybean leaves, whereas an increase was observed in $\Phi_{\mathrm{f}, \mathrm{D}}$ in cotton leaves.

The rate of electron transport through PSII, namely ETR (II), increased with PAR (Fig. 4). ETR (II) was greater in cotton than in soybean. Further, drought increased ETR (II) in cotton, but decreased it in soybean. Since ETR (II) is calculated from the product of $\Phi_{\mathrm{PSII}}$ and PAR, where $\Phi_{\mathrm{PSII}}=q P \times F_{\mathrm{v}}{ }^{\prime} / F_{\mathrm{m}}{ }^{\prime}$, we plotted each component of $\Phi_{\text {PSII }}$ in Fig. 5. Most notable features of these plots are a decrease of $q P$ in soybean (Fig. $5 a$ ) and an increase of $F_{\mathrm{v}}{ }^{\prime} / F_{\mathrm{m}}{ }^{\prime}$ in cotton (Fig. $5 b$ ) due to drought.

The ETR (I)/ETR (II) ratio exceeded 1, suggesting that CEF around PSI was functioning (Miyake et al. 2005). As shown in Fig. 6, soybean leaves had higher CEF than cotton leaves, and drought induced an increase in CEF in soybean leaves, but not in cotton.

\section{Discussion}

The difference between cotton and soybean leaves in leaf movement determines a different interception and utilisation of light energy under drought

In this study, soil drought reduced leaf water potential of cotton and soybean (Table 1). As previously reviewed by Chaves (1991), drought reduces leaf $\mathrm{CO}_{2}$ assimilation rate. Expectedly, droughtstressed cotton and soybean plants both had lower maximum $\mathrm{CO}_{2}$ assimilation rates than well-watered plants (Table 1); the extent of decrease for soybean was greater than that for cotton, indicating a greater loss of carbon assimilation capacity. According to the concept of excess energy (for details see Björkman and Demmig-Adams 1994; Oguchi et al. 2011), and given the similar initial slope (AQE) of the light response curve (Table 1; Fig. 2), for a given PAR, greater excess of excitation energy would be expected in the drought-stressed plants, especially in drought-stressed soybean. LCP in cotton and soybean decreased under drought to comparable extents. The lower LCP of both plants could be simply due to a lower dark respiration rate under drought (Table 1).

We noted that drought reduced LSP of both crop plants - more so in soybean than in cotton - which is in accordance with the observed differential diminution of light interception associated with leaf movement. Soybean exhibited paraheliotropic movement whereas cotton maintained diaheliotropic movement under drought, indicating that soybean leaves intercepted less sunlight than cotton leaves. Therefore, under drought, the photosynthetic apparatus of cotton leaves could utilise more light energy than those of soybean leaves. Thus, even though soybean had a lower capacity to utilise light energy, the excess light energy of soybean may be no higher than that of cotton in the field. As a result, leaf paraheliotropic movement in concert with photosynthetic characteristics can reduce the risk of photoinhibition under drought (Kao and Tsai 1998; Pastenes et al. 2004, 2005). Furthermore, Kao and Forseth (1991, 1992) have documented that regulating incident light on leaves to levels near the photosaturation level through paraheliotropic movement has the benefit of enhancing resources (e.g. water and nitrogen) use efficiency and photosynthetic carbon gain. Indeed, droughtstressed soybean had higher WUE than drought-stressed cotton and well-watered plants of both crops. Though drought reduced the PNUE of both crop plants (by $29 \%$ for soybean and $47 \%$ for cotton, Table 1), a smaller drop of the PNUE of soybean by drought was observed, indicating that soybean had the advantage of optimising nitrogen utilisation under drought.

\section{Soybean preferentially uses regulated non-photochemical energy dissipation whereas cotton uses electron transport flux for light energy dissipation under drought}

There are three main pathways of allocation of photons absorbed by the PSII antennae: photochemical conversion; light-regulated non-photochemical energy dissipation; and light-independent constitutive non-photochemical energy dissipation (Hendrickson et al. 2004). As shown in Fig. 3, the quantum yield of PSII was decreased and the regulated nonphotochemical energy dissipation increased in soybean under drought. This means that under drought, in moderate or high light, regulated non-photochemical energy dissipation was the main 


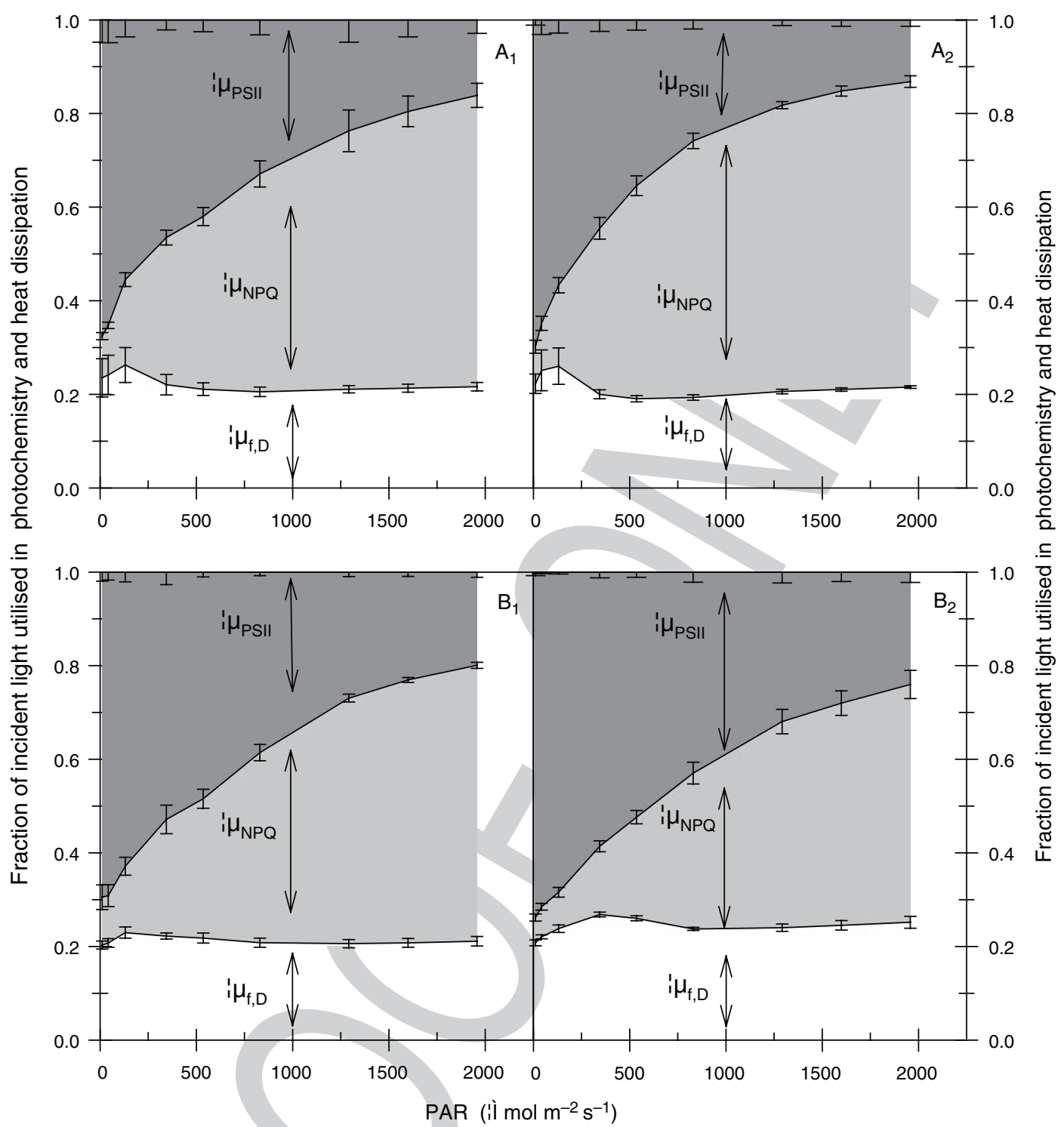

Fig. 3. Estimated fraction of absorbed PAR consumed via PSII photochemistry $\left(\Phi_{\mathrm{PSII}}\right), \Delta \mathrm{pH}$ - and xanthophyll-regulated thermal dissipation $\left(\Phi_{\mathrm{NPQ}}\right)$, and the sum of fluorescence and light-independent constitutive thermal dissipation $\left(\Phi_{\mathrm{f}, \mathrm{D}}\right)$, in $(a)$ leaves from well-watered soybean, $(b)$ drought-stressed soybean, $(c)$ well-watered cotton and $(d)$ drought-stressed cotton illuminated at varying PAR. Values are means \pm s.e. $(n=4)$.

pathway for light energy dissipation to provide photoprotection in soybean leaves. A similar result was reported by Inamullah and Isoda (2005b) in soybean. By contrast, the quantum yield of PSII was increased and the regulated non-photochemical energy dissipation was decreased in cotton under drought. Genty et al. (1987) have reported that PSII photochemistry of pot-grown cotton leaves is unaffected by drought, whereas Inamullah and Isoda (2005b) and Ennahli and Earl (2005) have shown that the PSII quantum yield of photochemistry in pot-grown cotton leaves are sometimes significantly affected and sometimes not, depending on the intensity of drought. However, in the field experiment, a higher efficiency of PSII photochemistry in cotton leaves under drought has been reported (Kitao and Lei 2007; Massacci et al. 2007). These results were consistent with our data.
Compared with pot-grown plants, field-grown plants generally suffer from multiple constraints because under field conditions; drought is often accompanied by other stresses such as heat stress and strong light (Havaux 1992). Furthermore, there was antagonism/synergism between heat, light and water deficit (Havaux 1992; Lu and Zhang 1999). In contrast, pot-grown plants, which generally suffer from 'short-term drought', do not include the phenomenon of acclimation which is usually well developed in field-grown plants (Panković et al. 1999). Therefore, the behaviour of pot-grown plants might be quite different from responses of plants in the field, and the capacity of field-grown plants to acclimate to drought can be greater than that of plants grown in pots (Plaut and Federman 1991; Havaux 1992). Thus, we propose that in the field, photochemical conversion is 


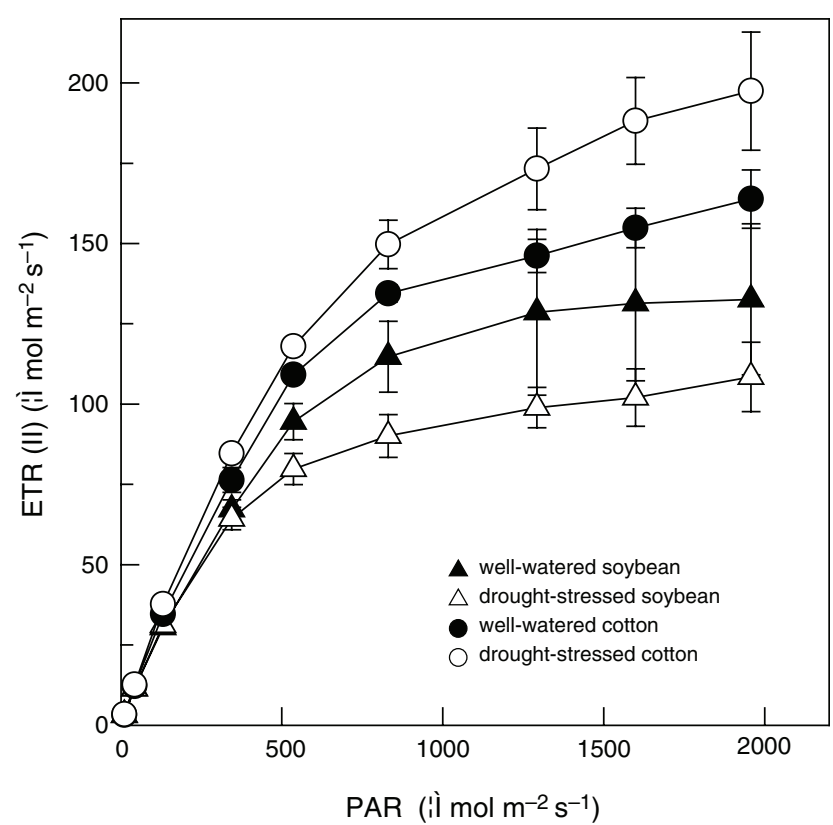

Fig. 4. Rapid light response curves of well-watered soybean, droughtstressed soybean, well-watered cotton and drought-stressed cotton. Values are means \pm s.e. $(n=4)$.

the main pathway for light energy dissipation to provide photoprotection in drought-stressed cotton leaves.

Using various indicators of non-photochemical energy dissipation, either no change (Genty et al. 1987; Inamullah and Isoda 2005b; Kitao and Lei 2007) or an enhancement (Massacci et al. 2007) was shown in cotton leaves under drought. In our study, regulated non-photochemical energy dissipation expressed as $\Phi_{\mathrm{NPQ}}=\left(F_{\mathrm{s}} / F_{\mathrm{m}}{ }^{\prime}\right)-\left(F_{\mathrm{s}} / F_{\mathrm{m}}\right)$ was decreased in drought-stressed cotton (Fig. $3 d$ ). $\Phi_{\mathrm{NPQ}}$ represents the fraction of the light energy dissipated thermally via $\Delta \mathrm{pH}-$ and xanthophylls-regulated processes, and is not identical with NPQ, the magnitude of which has no upper limit and sometimes over-evaluates its relative importance to photoprotection (Hendrickson et al. 2004). Taken together, our results demonstrate that the photosynthetic apparatus of cotton and soybean has different pathways to use or dissipate the energy absorbed by PSII antennae.

The difference in the distribution of photosynthetic electron transport flow between cotton and soybean under drought

Electron flow through PSII is consumed mainly by carbon assimilation, photorespiration and nitrogen assimilation (Badger 1985; Champigny 1995; Biehler and Fock 1996; Park et al. 1996). As shown in Figs 2, 4 and Table 1, carbon assimilation, photorespiration and electron transport rate of soybean leaves decreased in parallel under drought. By contrast, leaf electron transport rate in cotton responded differently to drought from soybean, increasing under drought conditions, despite the partial inhibition of $\mathrm{CO}_{2}$ assimilation capacity. Higher electron transport rate in cotton under drought has been reported previously (Kitao and Lei 2007;

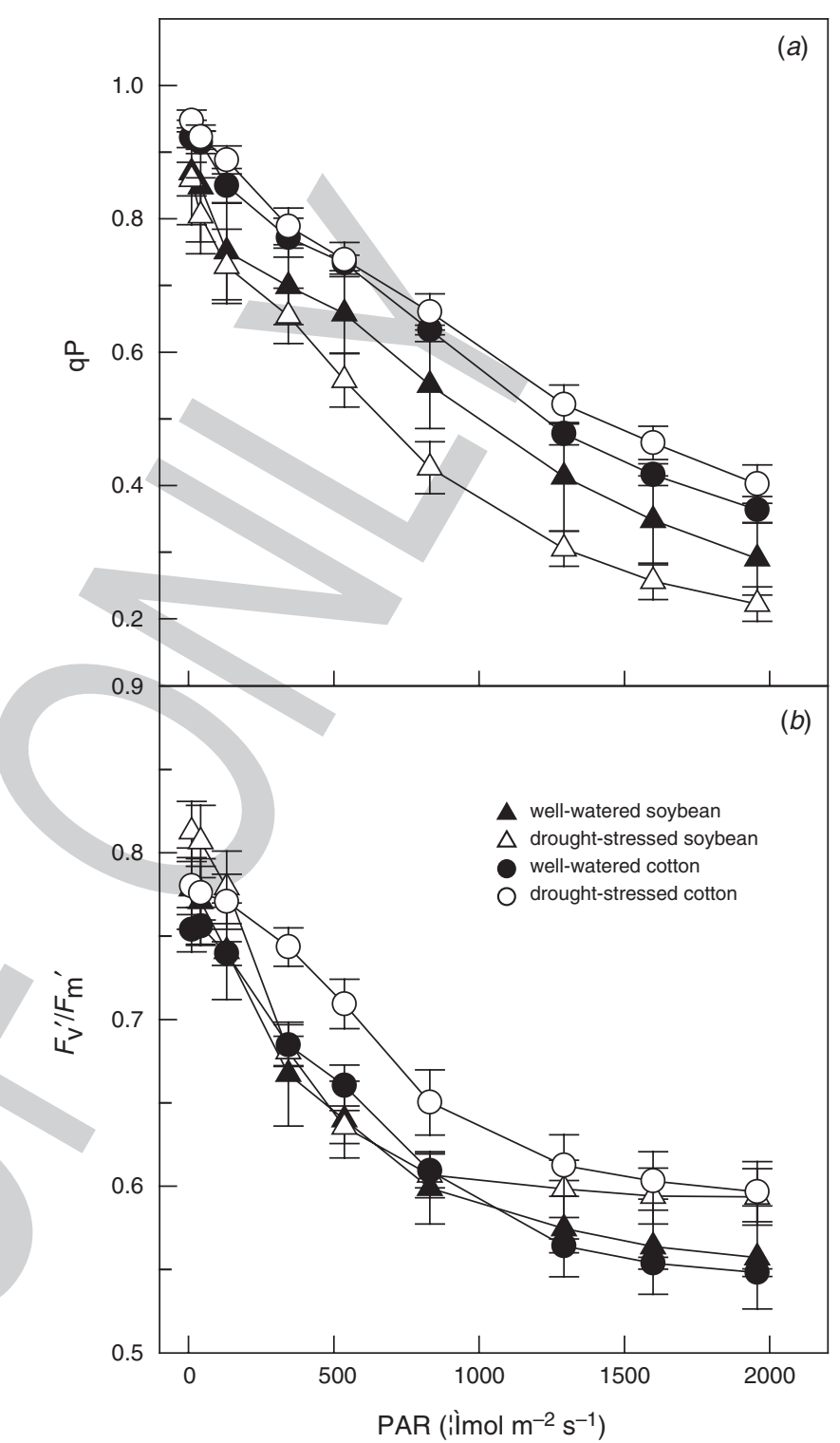

Fig. 5. Variation of $q P(\mathrm{~A})$ and $F_{\mathrm{v}}{ }^{\prime} / F_{\mathrm{m}}{ }^{\prime}$ with $\mathrm{PAR}$ in well-watered or drought-stressed soybean and well-watered or drought-stressed cotton. Values are means \pm s.e. $(n=4)$.

Massacci et al. 2007). As discussed by Massacci et al. (2007), it may be that photorespiration was enhanced by drought. In their experiment, however, photorespiration rate was estimated using combined measurements of gas exchange in the whole-leaf tissue and chlorophyll fluorescence. Since the measured chlorophyll fluorescence signal is predominantly emitted by chloroplasts nearer to the (adaxial) leaf surface, this method may not correctly represent the photorespiration rate in the whole-leaf tissue. In our study, we observed lower photorespiration as evaluated by the low oxygen $(2 \%)$ method, which was meant to give a qualitative estimation of photorespiration (Table 1); it appears that electron flow through PSII consumed by photorespiration was not increased but, if anything, decreased under drought-stressed cotton leaves, as was $A_{\max }$. If so, what 


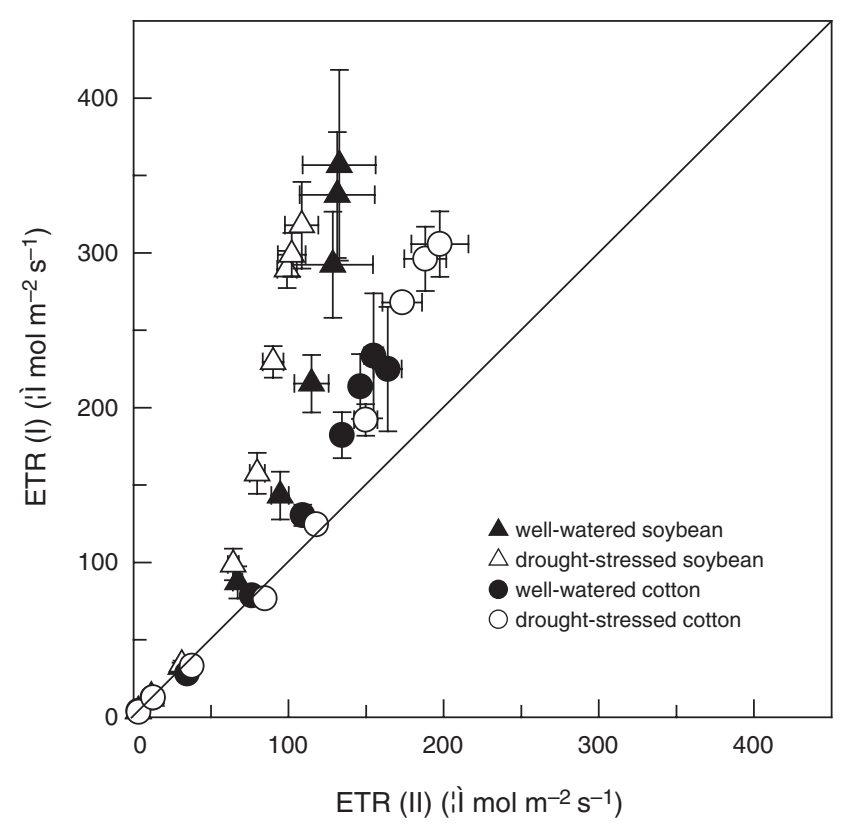

Fig. 6. ETR (II) and ETR (I) were determined simultaneously at varying PAR in leaves from well-watered soybean, drought-stressed soybean, wellwatered cotton and drought-stressed cotton. Values are means \pm s.e. $(n=4)$.

caused the increase in ETR (II) in drought-stressed cotton? We propose that electron flow through PSII is consumed mainly by nitrogen assimilation in drought-stressed cotton leaves. Nitrogen metabolism provides another sink for the energy harvested in photosynthesis (Larsson et al. 1982). For example, Kitao and Lei (2007) have shown that drought-stressed cotton leaves can maintain higher electron transport due to higher $N_{\text {area }}$ even while carbon assimilation was reduced. In our study, higher $N_{\text {area }}$ was indeed found in drought-stressed cotton leaves (Table 1). Nevertheless, lower PNUE was found as well. Feng et al. $(2007,2009)$ reported that PNUE was associated with not only $A_{\max }$ and $N_{\text {area }}$ but also nitrogen allocation and partitioning among different photosynthetic component. As the nitrogen allocated to photosynthesis was decreased, PNUE would decrease. Thus, further studies conducted in nitrogen allocation under drought-stressed both plants are necessary to explore the relationship between PNUE and nitrogen allocation for clarifying the distribution of photosynthetic electron flow in photosynthetic apparatus. Although further research is needed to elucidate activities of the enzymes involved, when taken together, we propose that nitrogen assimilation may be one of the main pathways that consume electron flow through PSII in droughtstressed cotton leaves, thereby protecting the photosynthetic apparatus from photodamage.

Enhanced nitrite reduction in the chloroplasts of droughtstressed cotton leaves, for example, could divert reduced ferredoxin away from CEF with some predictable consequences. First, there should be no increase in ferredoxindependent CEF (as observed in drought-stressed cotton, see below). Second, the diminution of CEF would minimise the contribution of $\mathrm{CEF}$ to the trans-membrane $\mathrm{pH}$ gradient, thereby restricting $\Phi_{\mathrm{NPQ}}$, as observed (Fig. 3d). Third, due to the restricted $\Phi_{\mathrm{NPQ}}$, the photochemical efficiency of open PSII traps $\left(F_{\mathrm{v}}{ }^{\prime} / F_{\mathrm{m}}{ }^{\prime}\right)$ should be increased, as observed (Fig. $5 b$ ). Fourth, the PQ pool should be slightly more oxidised when electrons are not fed into it from reduced ferredoxin, resulting in a more oxidised state of $\mathrm{Q}_{\mathrm{A}}$, or an increased $q P$, as observed (Fig. $5 a$ ).

Cyclic electron flow around PSI is also suggested to have an important role in photoprotection (Miyake et al. 2005). CEF may be involved in generating or maintaining a $\Delta \mathrm{pH}$ that is necessary for downregulation of PSII by thermal dissipation of excess absorbed light energy (Heber and Walker 1992). The CEFdependent photoprotection may occur via two mechanisms: one is linked to thermal energy dissipation and prevents the inhibition of the repair of photodamaged PSII at the step of protein synthesis; the other is independent of thermal energy dissipation and suppresses photodamage to PSII (Takahashi et al. 2009).

The ETR (I)/ETR (II) ratio in Fig. 6 was greater than 1 in both plants, more so in soybean than in cotton leaves. Since ETR (II), calculated from the product of $\Phi_{\mathrm{PSII}}$ and PAR is based on a chlorophyll fluorescence measurement, it represents the linear electron transport rate of chloroplasts nearer to the adaxial leaf surface, where a given incident light is not yet markedly attenuated; therefore, $q P$ (a measure of the oxidation state of the primary quinine acceptor in PSII) is lower than the average for the whole tissue. Consequently, since $\Phi_{\mathrm{PSII}}=q P \times F_{\mathrm{v}}{ }^{\prime} / F_{\mathrm{m}}{ }^{\prime}$ is under-estimated, ETR (II) obtained from the product of $\Phi_{\text {PSII }}$ and PAR tends to be an under-estimate for the tissue as a whole. However, ETR (I) is based on a P700 measurement using a measuring beam $(820 \mathrm{~nm})$ that readily penetrates and undergoes multiple scattering within the whole leaf tissue; it is a whole-tissue measurement (Losciale et al. 2008) of the total (linear + cyclic) electron flux through P700. Therefore, the ETR (I)/ETR (II) ratio is likely to be an overestimate of the ratio of (cyclic + linear) to linear electron flow. Even so, the observation that the ETR (I)/ ETR (II) ratio was greater than unity in both plant species suggests that cyclic electron flow was occurring, particularly in soybean under drought. In soybean, the higher CEF in drought-stressed leaves may have partly caused the enhanced regulated nonphotochemical energy dissipation $\left(\Phi_{\mathrm{NPQ}}\right.$, Fig. $\left.3 b\right)$ to confer photoprotection. The enhanced feedback of electrons to the PQ pool in CEF in soybean under drought, with restricted sinks such as nitrite reduction for draining electrons, would result in a more reduced PQ pool, and a lower $q P$, as observed (Fig. $5 a$ ).

In summary, soybean preferentially uses light-regulated nonphotochemical energy dissipation, which may have been enhanced by the higher CEF in drought-stressed leaves. In contrast, cotton appears to rely on enhanced electron transport flux for light energy utilisation under drought, for example, in enhanced nitrogen assimilation. Although the distributional mechanism of the electron transport chain under droughtstressed leaves of both crops requires further study, it can be concluded that soybean and cotton plants rely on contrasting photoprotective mechanisms to cope with drought.

\section{Acknowledgements}

This study was financially supported by the National Natural Science Foundation of China (Grant No. 30260051), by National Key Technology RandD Program of China (Grant No. 2006BAD21B02 and 2007BAD44B07) and by the Australian Research Council (DP1093827). 


\section{References}

Arena C, Vitale L, Virzo De Santo A (2008) Paraheliotropism in Robinia pseudoacacia L.: an efficient strategy to optimise photosynthetic performance under natural environmental conditions. Plant Biology 10, 194-201. doi:10.1111/j.1438-8677.2008.00032.x

Badger MR (1985) Photosynthetic oxygen exchange. Annual Review of Plant Biology 36, 27-53. doi:10.1146/annurev.arplant.36.1.27

Biehler K, Fock H (1996) Evidence for the contribution of the Mehlerperoxidase reaction in dissipating excess electrons in drought-stressed wheat. Plant Physiology 112, 265-272.

Bielenberg DG, Miller JD, Berg VS (2003) Paraheliotropism in two Phaseolus species: combined effects of photo flux density and pulvinus temperature, and consequences of leaf gas exchange. Environmental and Experimental Botany 49, 95-105. doi:10.1016/S0098-8472(02)00062-X

Björkman O, Demmig-Adams B (1994) Regulation of photosynthetic light energy capture, conversion, and dissipation in leaves of higher plants. Plant Physiology and Biochemistry 100, 17-47.

Champigny ML (1995) Integration of photosynthetic carbon and nitrogen metabolism in higher plants. Photosynthesis Research 46, 117-127. doi:10.1007/BF00020422

Chaves MM (1991) Effects of water deficits on carbon assimilation. Journal of Experimental Botany 42, 1-16. doi:10.1093/jxb/42.1.1

Ehleringer JR, Forseth IN (1980) Solar tracking by plants. Science 210, 1094-1098. doi:10.1126/science.210.4474.1094

Ehleringer JR, Hammond SD (1987) Solar tracking and photosynthesis in cotton leaves. Agricultural and Forest Meteorology 39, 25-35. doi:10.1016/0168-1923(87)90013-X

Ennahli S, Earl HJ (2005) Physiological limitations to photosynthetic carbon assimilation in cotton under water stress. Crop Science 45, 2374-2382. doi: $10.2135 /$ cropsci2 2005.0147

Feng YL, Auge H, Ebeling SK (2007) Invasive Buddleja davidii allocates more nitrogen to its photosynthetic machinery than five native woody species. Oecologia 153, 501-510. doi:10.1007/s00442-007-0759-2

Feng YL, Lei YB, Wang RF, Callaway RM, Valiente-Banuet A, Inderjit, Li YP, Zheng YL (2009) Evolutionary tradeoffs for nitrogen allocation to photosynthesis versus cell walls in an invasive plant. Proceedings of the National Academy of Sciences of the United States of America 106, 1853-1856.

Forseth IN, Ehleringer JR (1982a) Ecophysiology of two solar-tracking desert winter annuals. I. photosynthetic acclimation to growth temperature. Functional Plant Biology 9, 321-332.

Forseth IN, Ehleringer JR (1982b) Ecophysiology of two solar-tracking desert winter annuals. II. Leaf movement, water relation and microclimate. Oecologia 54, 41-49. doi:10.1007/BF00541105

Forseth IN, Ehleringer JR (1983) Ecophysiology of two solar-tracking desert winter annuals. III. Gas-exchange responses to light, $\mathrm{CO}_{2}$ and VPD in relation to long-term drought. Oecologia 57, 344-351. doi:10.1007/ BF00377179

Genty B, Briantais JM, Silva JBVD (1987) Effects of drought on primary photosynthetic processes of cotton leaves. Plant Physiology 83, 360-364. doi:10.1104/pp.83.2.360

Genty B, Briantais JM, Baker NR (1989) The relationship between the quantum yield of photosynthetic electron transport and quenching of chlorophyll fluorescence. Biochimica et Biophysica Acta 990, 87-92.

Havaux M (1992) Stress tolerance of photosystem II in vivo: antagonistic effects of water, heat and photoinhibition stresses. Plant Physiology 100, 424-432. doi:10.1104/pp.100.1.424

Heber U, Walker D (1992) Concerning a dual function of coupled cyclic electron transport in leaves. Plant Physiology 100, 1621-1626. doi:10.1104/pp.100.4.1621

Hendrickson L, Furbank RT, Chow WS (2004) A simple alternative approach to assessing the fate of absorbed light energy using chlorophyll fluorescence. Photosynthesis Research 82, 73-81. doi:10.1023/B: PRES.0000040446.87305.f4
Inamullah, Isoda A (2005a) Adaptive responses of soybean and cotton to water Q3 stress. I. Transpiration changes in relation to stomatal area and stomatal conductance. Plant Production Science 8, 16-26. doi:10.1626/pps.8.16

Inamullah, Isoda A (2005b) Adaptive responses of soybean and cotton to Q3 water stress. II. Changes in $\mathrm{CO}_{2}$ assimilation rate, chlorophyll fluorescence and photochemical reflectance index in relation to leaf temperature. Plant Production Science 8, 131-138. doi:10.1626/ pps.8.131

Isoda A, Wang PW (2002) Leaf temperature and transpiration of field grown cotton and soybean under arid and humid conditions. Plant Production Science 5, 224-228. doi:10.1626/pps.5.224

Kao WY, Forseth IN (1991) The effects of nitrogen, light and water availability on tropic leaf movement in soybean (Glycine max). Plant, Cell \& Environment 14, 287-293. doi:10.1111/j.1365-3040.1991. tb01503.x

Kao WY, Forseth IN (1992) Diurnal leaf movement, chlorophyll fluorescence and carbon assimilation in soybean grown under different nitrogen and water availabilities. Plant, Cell \& Environment 15, 703-710. doi:10.1111/ j.1365-3040.1992.tb01012.x

Kao WY, Tsai TT (1998) Tropic leaf movements, photosynthetic gas exchange, leaf $\delta^{13} \mathrm{C}$ and chlorophyll a fluorescence of three soybean species in response to water availability. Plant, Cell \& Environment 21, 1055-1062. doi:10.1046/j.1365-3040.1998.00333.x

Kitao M, Lei TT (2007) Circumvention of over-excitation of PSII by maintaining electron transport rate in leaves of four cotton genotypes developed under long-term drought. Plant Biology 9, 69-76. doi:10.1055/ s-2006-924280

Kornyeyev D, Logan BA, Allen RD, Holaday AS (2005) Field-grown cotton plants with elevated activity of chloroplastic glutathione reductase exhibit no significant alteration of diurnal or seasonal patterns of excitation energy partitioning and $\mathrm{CO}_{2}$ fixation. Field Crops Research 94, 165-175. doi:10.1016/j.fcr.2005.01.001

Krause GH, Weis E (1991) Chlorophyll fluorescence and photosynthesis: the basics. Annual Review of Plant Biology 42, 301-313.

Larsson M, Ingemarsson B, Larsson CM (1982) Photosynthetic energy supply for $\mathrm{NO}_{3}^{-}$assimilation in Scenedesmus. Physiologia Plantarum 55, 301-308. doi:10.1111/j.1399-3054.1982.tb00296.x

Long SP, Humphries S, Falkowski PG (1994) Photoinhibition of photosynthesis in nature. Annual Review of Plant Biology 45, 633-662. doi:10.1146/annurev.pp.45.060194.003221

Losciale P, Oguchi R, Hendrickson L, Hope AB, Corelli-Grappadelli L, Chow WS (2008) A rapid, whole-tissue determination of the functional fraction of PSII after photoinhibition of leaves based on flash-induced P700 redox kinetics. Physiologia Plantarum 132, 23-32.

Lu CM, Zhang JH (1999) Effects of water stress on photosystem II photochemistry and its thermostability in wheat plants. Journal of Experimental Botany 50, 1199-1206. doi:10.1093/jexbot/50.336.1199

Massacci A, Nabiev SM, Pietrosanti L, Nematov SK, Chernikova TN, Thor K, Leipner J (2007) Response of the photosynthetic apparatus of cotton (Gossypium hirsutum) to the onset of drought stress under field conditions studied by gas-exchange analysis and chlorophyll fluorescence imaging. Plant Physiology and Biochemistry 46, 1-7.

Miyake C, Miyata M, Shinzaki Y, Tomizawa K (2005) $\mathrm{CO}_{2}$ response of cyclic electron flow around PSI (CEF-PS I) in tobacco leaves - relative electron fluxes through PSI and PSII determine the magnitude of nonphotochemical quenching (NPQ) of Chl fluorescence. Plant \& Cell Physiology 46, 629-637. doi:10.1093/pcp/pci067

Oguchi R, Terashima I, Kou J, Chow WS (2011) Operation of dual mechanisms that both lead to photoinactivation of photosystem II in leaves by visible light. Physiologia Plantarum 142, 47-55. doi:10.1111/ j.1399-3054.2011.01452.x

Oxborough K, Baker NR (1997) Resolving chlorophyll a fluorescence images of photosynthetic efficiency into photochemical and non-photochemical components-calculation of $q P$ and $F_{\mathrm{v}}{ }^{\prime} / F_{\mathrm{m}}{ }^{\prime}$ without measuring $F_{\mathrm{o}}{ }^{\prime}$. Photosynthesis Research 54, 135-142. doi:10.1023/A:1005936823310 
Panković D, Sakač Z, Kevrešan S, Plesničar M (1999) Acclimation to longterm water deficit in the leaves of two sunflower hybrids: photosynthesis, electron transport and carbon metabolism. Journal of Experimental Botany 50, 127-138. doi:10.1093/jexbot/50.330.127

Park YI, Chow WS, Osmond CB, Anderson JM (1996) Electron transport to oxygen mitigates against the photoinactivation of photosystem II in vivo. Photosynthesis Research 50, 23-32. doi:10.1007/BF00018218

Pastenes C, Porter V, Baginsky C, Horton P, Javiera G (2004) Paraheliotropism can protect water-stressed bean (Phaseolus vulgaris L.) plants against photoinhibition. Journal of Plant Physiology 161, 1315-1323. doi:10.1016/j.jplph.2003.09.002

Pastenes C, Pimentel P, Lillo J (2005) Leaf movement and photoinhibiton in relation to water stress in field-grown beans. Journal of Experimental Botany 56, 425-433. doi:10.1093/jxb/eri061

Perry SW, Krieg DR, Hutmacher RB (1983) Photosynthetic rate control in cotton. Plant Physiology 73, 662-665. doi:10.1104/pp.73.3.662

Plaut Z, Federman E (1991) Acclimation of $\mathrm{CO}_{2}$ assimilation in cotton leaves to water stress and salinity. Plant Physiology 97, 515-522. doi:10.1104/ pp.97.2.515

Sailaja MV, Ramadas VS (1996) Leaf solar tracking response exhibits diurnal constancy in photosyntem II efficiency. Environmental and Experimental Botany 36, 431-438. doi:10.1016/S0098-8472(96)01020-9
Schreiber U, Klughammer C (2008) Non-photochemical fluorescence quenching and quantum yields in PSI and PSII: analysis of heatinduced limitations using Maxi-Imaging-PAM and Dual-PAM-100. PAM Application Notes 1, 15-18.

Schreiber U, Bilger W, Neubauer C (1994) Chlorophyll fluorescence as a nonintrusive indicator for rapid assessment of in vivo photosynthesis. In 'Ecophysiology of photosynthesis'. (Eds ED Schulze, MM Caldwell) pp. 49-70. (Springer-Verlag: Berlin)

Schuman GE, Stanley MA, Knudsen D (1972) Automated total nitrogen analysis of soil and plant samples. Proceedings - Soil Science Society of America 37, 480-481. doi:10.2136/sssaj1973.03615995003700030045x

Takahashi S, Milward SE, Fan DY, Chow WS, Badger MR (2009) How does cyclic electron flow alleviate photoinhibition in Arabidopsis? Plant Physiology 149, 1560-1567. doi:10.1104/pp.108.134122

Manuscript received 9 March 2011, accepted 26 May 2011

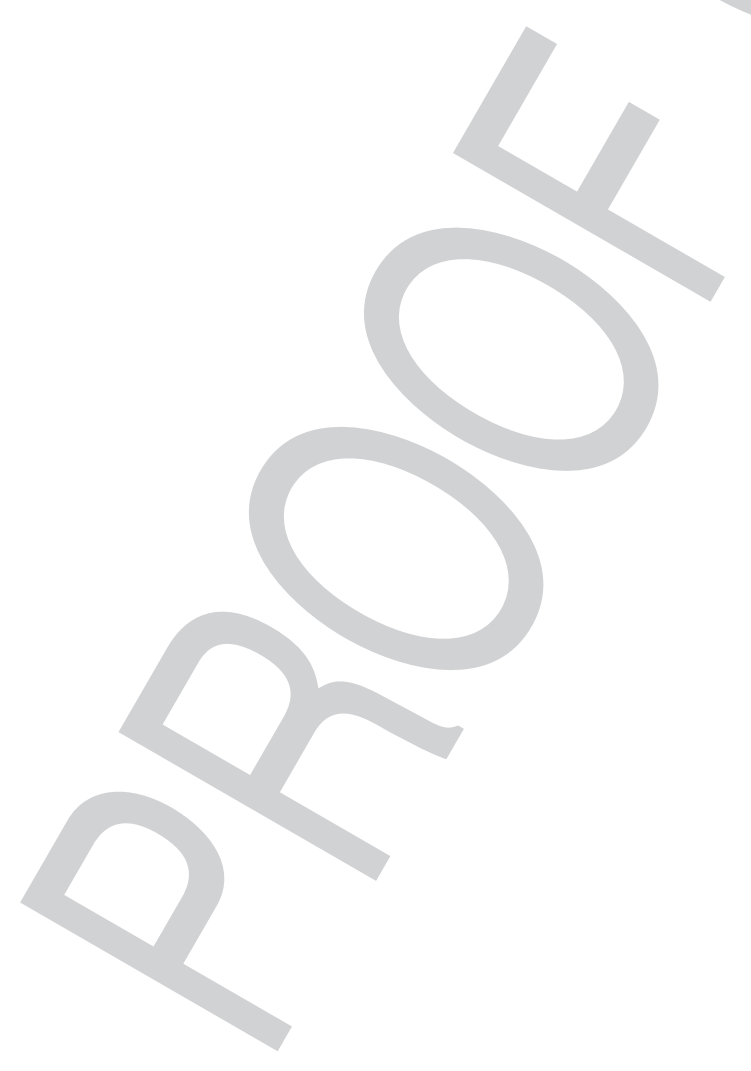




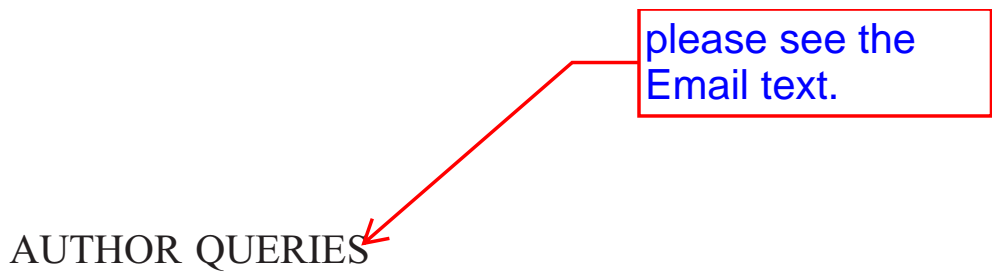

1. Author: Please supply a short title of no more than 50 characters long (including spaces).

2. Author: Please suggest, whether we can change $A_{1}, A_{2}, B_{1}, B_{2}$ to $a, b, c, d$ as indicated in Figure caption.

3. Author: Please provide firstname for Refs. Inamullah. 